\title{
O conceito de bem-estar na teoria econômica convencional
}

\author{
Fernanda Calasans C. L. Pessoti ${ }^{1}$ \\ Edna Maria Silva ${ }^{2}$
}

\begin{abstract}
Resumo: Este trabalho analisa o conceito de bem-estar empregado pela teoria econômica do bem-estar. O objetivo principal é ressaltar que a definição de bem-estar, tanto aquela empregada pela economia tradicional, quanto pela moderna economia do bem-estar, fundamenta-se no comportamento racional e maximizador do indivíduo, que pouca relação possui com o comportamento real desse indivíduo na sociedade. As principais contribuições teóricas da economia do bem-estar são apresentadas, destacando as ideias utilitaristas e de Vilfredo Pareto. O refinamento conceitual realizado por Pareto não foi capaz de incorporar aspectos importantes que influenciam o comportamento do indivíduo. Ainda assim, seu argumento de otimalidade e eficiência econômica predomina no pensamento econômico ortodoxo e baliza muitas das políticas de bem-estar.
\end{abstract}

Palavras-chave: Economia do bem-estar. Racionalidade. Utilitarismo.

Abstract: This paper analyses the welfare concept used by the Welfare Economic Theory. The main objective is to emphasize that the definition of well-being, both that used by the traditional economy and the modern welfare economy, is based on the rational and maximizing behaviour of the individual, which has little relation to the real behaviour of this individual in society. The main theoretical contributions of the welfare economy are presented, highlighting the utilitarian and Vilfredo Pareto ideas. The Pareto conceptual refinement was not able to incorporate important aspects that influence the behaviour of the individual. Still, his argument for optimality and economic efficiency predominates in orthodox economic thinking and beacon many welfare policies.

Keywords: Welfare economics. Rationality. Utilitarianism.

\footnotetext{
1 Doutoranda em Economia (PPGE-UFBA). Professora Assistente do DCSA (UESB). E-mail: fecalasans@gmail.com.

2 Doutoranda em Economia (PPGE-UFBA). Professora Assistente do Departamento de Medicina Veterinária Preventiva e Produção Animal. (UFBA). E-mail: ednasilv@yahoo.com.br.
} 


\section{Introdução}

O termo bem-estar é frequentemente encontrado em textos publicados nas diversas áreas do pensamento econômico. Em um primeiro momento, é quase sempre associado à ideia de melhoria, seja do ponto de vista das condições sociais, seja no que se refere aos aspectos estritamente econômicos.

No entanto, a intersecção entre esses dois pontos - melhoria das condições sociais e eficiência econômica - pode resultar em uma definição de bem-estar que se distancia do senso comum. Dentro da própria ciência econômica, existem várias definições para o termo bem-estar. Assim, é fundamental conhecer o conceito de bem-estar que está sendo empregado ao desenvolver as análises.

Com base no reconhecimento que este conceito possui para a análise econômica, este trabalho apresenta a definição de bem-estar utilizada pela Teoria Econômica tradicional do Bem-estar, "[...] área do conhecimento econômico dedicada ao estudo dos diferentes métodos de avaliação do bem-estar social e sua aplicação na comparação de diferentes estados da Economia” (GARCIA, 1996, p. 14). Esta teoria está baseada nas ideias utilitaristas e se constitui no pensamento dominante do mainstream econômico, o que justifica o olhar atento para suas formulações.

O objetivo do artigo é demonstrar que, embora constantemente empregado, o conceito de bemestar é pouco debatido e tem cada vez mais se distanciado da ideia de melhoria das condições de vida da população, focando quase que exclusivamente na busca pela eficiência econômica. Ainda que a melhoria do padrão de vida envolva ganhos econômicos, tal padrão envolve fatores multidimensionais que muitas vezes não são considerados pelos fundamentos microeconômicos que servem de base para a análise convencional de bem-estar.

Convém ressaltar que não é proposta deste trabalho esgotar todas as formulações e questionamentos que a Teoria tradicional do Bem-estar suscitou ao longo do seu desenvolvimento. Entretanto, espera-se incitar o debate para a importância que os conceitos econômicos desempenham tanto nas formulações teóricas, quanto nas indicações de políticas e análises econômicas.

O trabalho está dividido em três seções, além desta introdução. A seção seguinte trata do desenvolvimento da Teoria Econômica do Bem-estar, destacando suas principais contribuições. A terceira seção apresenta as principais críticas ao conceito de bem-estar baseado na eficiência econômica e na agregação de utilidades. A última seção traz as considerações finais. 


\section{O bem-estar na teoria econômica}

As primeiras formulações da Teoria Econômica do Bem-estar tiveram como base o individualismo metodológico, sendo o conceito de bem-estar centrado na avaliação do bem-estar (wellbeing) do indivíduo. Este conceito foi fortemente influenciado pelas ideias utilitaristas, em especial pelas de Jeremy Bentham, tendo, portanto, emergido de outro campo de estudo que não a própria Economia, a saber, a filosofia.

No entanto, diferentemente do que havia sido advogado pelos filósofos utilitaristas, a Economia Neoclássica, à qual muitos dos economistas da Teoria Econômica do Bem-estar estavam vinculados, associou a centralidade no indivíduo à concepção de hedonismo egoísta, no sentido de que a utilidade representava a maximização da felicidade pessoal, sem considerar as questões éticas (SEN, 1999; GARCIA, 1996).

De acordo com Sen (1999), o utilitarismo como princípio moral, possui três elementos básicos: welfarism (welfarismo), sum-ranking (ranking pela soma) e o consequentialism (consequencialismo). O welfarism é “[...] a concepção de que as únicas coisas de valor intrínseco para o cálculo ético e a avaliação dos estados são as utilidades individuais" (SEN, 1999, p. 56). O sum-ranking estabelece que o somatório das utilidades de determinado estado é a base de avaliação para as informações sobre utilidade relativas a este estado. Já o consequentialism determina que as escolhas dependem do quanto o estado de coisas decorrentes será benéfico (SEN, 1999).

Para Blackorby, Bossert e Donaldson (1999, p. 1), o utilitarismo

[...] is a welfarist principle that can be used to rank social alternatives according to their godness. Utility is an index individual lifetime well-being and, for fixed population, Utilitarism declares alternative $x$ to be better that alternative $y$ if and only if total utility is greater in $x$ than in $y$.

$\mathrm{Na}$ perspectiva do individualismo metodológico, o indivíduo é visto como um ser naturalmente racional que age visando o auto interesse e, ao agir assim, garante o bem-estar coletivo. Ou seja, admite-se que o indivíduo possui características naturais intrínsecas que o levam a agir de forma racional, características estas que não são determinadas pelo contexto histórico em que ele está inserido. Dentre essas características, está a propensão à troca, que motiva o estabelecimento de relações comerciais entre os indivíduos. Fatores que inibam a liberdade do indivíduo em atuar no sistema econômico são compreendidos como violação ao direito natural.

Um terceiro elemento deve ser adicionado àqueles que fundamentaram a constituição da Teoria do Bem-estar. Trata-se do comportamento racional, que foi adotado por número expressivo de 
economistas como a representação do comportamento real. Sen (1999) aponta dois métodos predominantes para a definição do comportamento racional: i) o método de consistência interna de escolha, representado pela função utilidade do indivíduo; ii) o método de maximização do auto interesse, que advoga que a maximização do auto interesse é o único comportamento racional que se deve esperar do indivíduo.

Entre as primeiras contribuições à teoria do Bem-estar, está o modelo proposto por Walras. Para Reis (2016), Walras fez uma síntese de quatro proposições que muito influenciaram os pensadores econômicos do século XIX. Trata-se da Fábula das Abelhas, de Bernard de Mandeville; da mão invisível, mencionada por Adam Smith; da lei de Say, segundo a qual toda oferta gera sua própria demanda; e do utilitarismo de Bentham. Essa estrutura de análise atendia às prerrogativas da ciência moderna, bem como aos princípios políticos liberais de liberdade individual e de Estado mínimo.

Com base no individualismo metodológico e na racionalidade, Walras demonstrou a existência de uma lei natural que governa a organização econômica das sociedades através de um sistema de equações capaz de expressar o mundo real em números. Esse sistema está centrado nas ações dos indivíduos que são livres para comercializar, empreender, os quais jamais deveriam ter sua liberdade cerceada por lei.

Deste modo, Walras foi o teórico que desenvolveu a construção do modelo de equilíbrio geral, fundamentado em pressupostos como a autonomia individual dos agentes, racionalidade, mercado de concorrência perfeita e considerando que os recursos produtivos são distribuídos entre os proprietários dos fatores de produção, o que permitiria que o sistema econômico chegasse a um resultado de equilíbrio de pleno emprego. Assim, a partir da ação individual e maximizadora dos agentes (máximo de bem-estar possível), dados os recursos disponíveis, a tecnologia e os gostos e preferências dos consumidores, alcançar-se-ia o máximo das possibilidades produtivas da sociedade (REIS, 2016).

O modelo desenvolvido por Walras recebeu críticas de alguns teóricos e foi aprimorado por outros, a exemplo de Vilfredo Pareto, que deu relevante contribuição lógica ao modelo de Equilíbrio Geral. Autores como Bergson, Kaldor, Samuelson, Arrow, dentre outros, também contribuíram para o desenvolvimento e aprofundamento da Teoria do Bem-estar social.

Dentre as contribuições de Pareto à Ciência Econômica destacam-se três para esta análise: a criação de uma teoria ordinal de bem-estar; o desenvolvimento da teoria do equilíbrio geral de Walras; e a criação de um critério de avaliação do bem-estar social (Ótimo de Pareto), que inaugurou uma nova linha de pesquisa (GARCIA, 1996).

Segundo Garcia (1996), Pareto partiu do conceito de utilidade marginal desenvolvido por Jevons, Menger e Walras. A utilidade marginal é o adicional de utilidade proveniente do incremento de consumo, que seria positivo e decrescente. Como a utilidade, nessa abordagem, está relacionada com o consumo, há uma restrição ao seu crescimento imposta pela renda, pois não é possível consumir para além do limite de renda (Lei de Walras). Com isso, a escolha do consumidor foi "concebida como um problema de maximização da função utilidade sujeita à restrição orçamentária da família” (GARCIA, 1996, p. 8). 
Do processo de maximização da utilidade do consumidor se deriva a função demanda - a relação entre preço e quantidade consumida - que é chave na determinação do equilíbrio de mercado. À luz do entendimento de Garcia (1996, p. 8), “Ao maximizar seu bem-estar, o consumidor igualava a utilidade marginal de uma unidade adicional de renda, denotada por $\mu$, com as relações entre utilidade marginal e preço dos bens consumidos" (GARCIA, 1996, p. 8).

Essa estrutura de análise dependia de se conhecer ex-ante a função utilidade e o nível de bem-estar do consumidor. As críticas de Pareto à teoria da utilidade eram direcionadas à própria existência de uma medida de bem-estar e à possibilidade de comparações interpessoais de bem-estar. A mensurabilidade do nível de bem-estar dos agentes era algo muito questionado por ele. Ainda assim, Pareto reconheceu a importância das antigas teorias econômicas para o desenvolvimento da ciência, consoante esboçado, verbis:

\begin{abstract}
As teorias da antiga Economia eram necessárias para se chegar às teorias novas e estas, sempre muito imperfeitas, servir-nos-ão para chegar a outras que o serão menos, e assim por diante. Aperfeiçoar uma teoria é diferente de querer destrui-la por tolas e pedantes sutilezas; o primeiro trabalho é uma coisa sensata e útil, o segundo é coisa pouco razoável e vã, e quem não tem tempo a perder faz melhor se não cuidar disso (PARETO, 1996, p. 131).
\end{abstract}

Para superar os problemas de mensurabilidade, Pareto desenvolveu a abordagem da escolha dos agentes econômicos partindo das curvas de indiferença de Edgeworth, instrumental da teoria da utilidade, unindo economia e matemática. De acordo com Garcia (1996, p. 10), Pareto

[...] desenvolveu uma nova abordagem da escolha dos agentes econômicos, que mantinha os principais resultados da visão dominante e prescindia de uma função utilidade mensurável. Sua teoria, que tornou clara a noção de preferência, empregava o conceito ordinal de bem-estar.

Entretanto, há uma diferença na relação entre utilidade e curvas de indiferença na visão paretiana e na visão de Edgeworth, diferença exposta pelo próprio Pareto (1996, p. 139):

[...] Ele [Edgeworth] supunha a existência da utilidade (ofelimidade) e daí deduzia as curvas de indiferença; eu, ao contrário, considero as curvas de indiferença como um dado de fato e daí deduzo tudo que me é necessário para a teoria do equilíbrio, sem recorrer à ofelimidade.

As curvas de indiferença de Edgeworth mostravam como os bens $x=\left(x_{1}, x_{2}, \ldots, x_{n}\right)$ poderiam ser combinados, mantendo o bem-estar do consumidor no mesmo patamar. Ou seja, considerando que os bens poderiam ser trocados uns pelos outros, a curva de indiferença apontava para as eventuais trocas que 
o consumidor, de acordo com suas preferências, estaria disposto a fazer, mantido constante seu nível de bem-estar.

Dessa forma, o conjunto das curvas de indiferença do consumidor que formam o mapa de indiferença continha as informações necessárias à escolha, o que dispensava conhecer a priori a função utilidade. Para tanto, seria necessário associar um índice a cada curva de indiferença do mapa, de tal forma que duas combinações entre as quais a escolha é indiferente devem ter o mesmo índice; e dentre duas combinações, aquela que for preferida, a outra deve ter o maior índice (GARCIA, 1996). Assim, segundo Garcia (1996, p. 10),

[...] as várias combinações de bens estariam ordenadas segundo as preferências do consumidor, e sua escolha se resumiria em selecionar a combinação com o maior índice — a preferida — entre aquelas acessíveis a sua renda [...].

A função utilidade é consequência dos pressupostos da teoria ordinal e não uma hipótese primária de trabalho.

Além da introdução do enfoque ordinal de preferências na análise do comportamento do consumidor, Pareto considerou os diversos agentes - consumidores, produtores, Estado e sociedade como entidades semelhantes em essência. Todos eles eram motivados pela satisfação do auto interesse, utilizando dos meios disponíveis a cada um. As preferências de cada tipo de agente poderiam ser distintas, mas todos eles tinham o mesmo objetivo e estavam sujeitos a restrições. $\mathrm{O}$ comportamento econômico passou a ser visto como a contraposição entre preferências e restrições desde então (GARCIA, 1996).

A contribuição de Pareto para a Teoria Econômica do Bem-estar não se limitou à mensuração da utilidade, avançando para unir o estudo do equilíbrio geral com as propriedades de bem-estar coletivo da economia. Na sua visão crítica, estabelecer comparações interpessoais de bem-estar era um abuso lógico e permitia julgamentos de valor moral duvidoso. Considerando que não é possível comparar sensações de prazer e de sofrimentos e somá-las, tal como suponha o critério tradicional da economia do bem-estar (SEN, 1999), Pareto contestou essa possibilidade e introduziu o conceito ordinal de bem-estar social.

Nesse sentido, comparações de bem-estar só seriam possíveis se, e somente se, fosse impossível aumentar a utilidade de uma pessoa sem reduzir a utilidade de outra (GARCIA, 1996; SEN, 1999).

Nas palavras de Garcia (1996), o critério paretiano de avaliação do bem-estar social estabelecia que:

a) [...] um estado é superior a outro se é possível aumentar o bem-estar de pelo menos um indivíduo sem prejudicar os demais (Superioridade de Pareto);

b) o bem-estar de uma sociedade é máximo se não existe outro estado tal que seja possível aumentar o bem-estar de um indivíduo sem diminuir o bem-estar dos demais; isto é, não há forma de melhorar a situação de um, sem prejudicar a situação dos outros (Ótimo de Pareto) (GARCIA, 1996, p.13). 
Com a aplicação desses critérios na análise das propriedades do equilíbrio geral, Pareto provou que, independentemente da distribuição de recursos iniciais, todo equilíbrio geral de uma economia em concorrência perfeita maximiza o bem-estar da sociedade - primeiro teorema da Economia do Bem-Estar. Ademais, ele indicou que "toda situação ótima no sentido de Pareto pode ser atingida por um equilíbrio competitivo, dada uma distribuição inicial de recursos apropriada" (GARCIA, 1996, p. 13) - proposição conhecida como segundo teorema da Economia do Bem-Estar.

Pareto deixou evidente na sua análise que o equilíbrio de uma economia em concorrência perfeita leva ao máximo de bem-estar da sociedade, reforçando a defesa de liberdade econômica e não intervenção no mercado. Dado que cada estado social Pareto-ótimo é um equilibrio perfeitamente competitivo, tal instrumento analítico "[...] permite discernir profundamente a natureza do funcionamento do mecanismo de preços, explicando a natureza mutuamente vantajosa da troca, produção e consumo regidos pelo auto interesse" (SEN, 1999, p. 50). Com essa inovação analítica é possível comparar diferentes estados da economia, a partir da observação do bem-estar de cada indivíduo, ou seja, se em uma situação o bem-estar é maior ou menor do que em outra (GARCIA, 1996).

Seguindo as ideias apresentadas por Walras e Pareto, outros autores também trouxeram relevantes contribuições para a Economia do Bem-estar social. De acordo com Ganem (1996), Abram Bergson, em 1938, foi um dos primeiros autores a apresentar uma relação entre o equilíbrio walrasiano e a otimalidade paretiana por intermédio de uma função de bem-estar social. Esse teórico exerceu influência sobre os trabalhos de Lange, Samuelson e Arrow. Posteriormente, Arrow, Debreu e Koopmans também desenvolverem um modelo que aliava o equilíbrio geral com as contribuições de Pareto e demonstraram que todo equilíbrio concorrencial é um ótimo de Pareto.

Araújo e Mendonça (2003) afirmam que a contribuição de Bergson à análise econômica consistiu em incorporar a função de bem-estar social para a escolha da política ótima. Segundo esses autores, "na interpretação de Bergson, a função de bem-estar social seria capaz de permitir a um planejador governamental incorporar à sua função objetivo a visão individualista e ética do economista como forma de obter um máximo bem-estar social" (ARAÚJO; MENDONÇA, 2003, p. 9).

Esta função de bem-estar depende de juízo de valor, pois um bem-estar máximo está relacionado ao pensamento do político mandatário. Na concepção de Bergson, um aumento no nível de satisfação de uma comunidade indica um aumento em seu bem-estar (SOUSA, 2011). De acordo com Souza (2011, p. 23),

Para melhor explicar o nível de satisfação de uma comunidade, Bergson faz uso de um mapa de indiferença que foi denominado de funções de bem-estar social. Essas funções obedecem às regras das curvas de indiferença para proporcionar um melhoramento definitivo, isto é, são côncavas à origem, não interceptam etc. 
Com base na definição de Bergson da função de bem-estar social, Samuelson elaborou, em 1947, uma análise na qual o critério de valor foi incorporado na análise econômica (ARAÚJO; MENDONÇA, 2003). Considerando que a racionalidade dos indivíduos permite que eles saibam o que é melhor para si mesmos, o problema da escolha individual não é relevante. No entanto, a questão da escolha social ou coletiva traz alguns questionamentos sobre o que seria melhor para a coletividade e como julgar quais critérios seriam aplicados ao processo de escolha.

Outro teórico que também trouxe contribuição relevante para a economia do bem-estar foi Arrow (1951), que buscou analisar o processo por meio do qual a função de bem-estar social de Bergson e Samuelson poderia ser alcançada (ARAÚJO, MENDONÇA, 2003).

Nicholas Kaldor ao estudar a economia do bem-estar, estabeleceu o critério da compensação. Segundo este critério, “[...] uma mudança é uma melhoria se, a pessoa que ganha, avalia seus ganhos a um valor mais alto da unidade monetária, do que o valor desta, para os perdedores" (SOUZA, 2011, p. 21). Ou seja, aquele que ganha compensa as perdas dos perdedores, deixando-os em melhores condições que antes. O critério de Kaldor é um aprimoramento do critério de Pareto, já que a compensação aos perdedores garante que todos participantes do sistema saiam ganhando ou, no mínimo, permaneçam melhores do que antes. Para Kaldor, se os ganhadores compensam os perdedores de forma que resulte um ganho líquido, então uma variação constitui uma melhoria de eficiência econômica ou de bem-estar social (SOUSA, 2011).

Com base no argumento que nem sempre todas as condições de Pareto são atendidas, Lipsey e Lancaster "[...] criaram a teoria do segundo melhor que trata de uma situação na qual uma ou mais condições de Pareto não podem ser atendidas" (SOUZA, 2011, p. 26). Em situações como estas, faz-se necessário buscar outra forma de ajustar a economia que não seja pela otimização.

O teorema geral para o segundo melhor estabelece que

[...] that if there is introduced into a general equilibrium system a constraint which prevent the attainment of one the Paretian conditions, the other Paretian conditions, although still attainable, are, in general, no longer desirable. In other words, given that one of the Paretian optimum conditions cannot be fulfilled, then an optimum situation can be achieve only by departing from all the other Paretian conditions. The optimum situation finally attained may be termed a second best optimum because it is achieve subject to a constraint which, by definitions, prevent the attainment of a Paretian optimum (LIPSEY; LANCASTER, 1956, p. 11).

Nota-se que, na verdade, o segundo melhor ótimo (second best optimum) é um ótimo de Pareto com restrições adicionais. 
As contribuições posteriores à teoria do Bem-Estar tentam aprimorar as limitações da análise paretiana de otimização. Há uma vasta literatura internacional que analisa os problemas relativos à questão de agregar preferências individuais para maximizar uma dada função de bem-estar social, ou satisfazer a algum aspecto normativo.

$\mathrm{Na}$ Economia moderna do Bem-estar, o ponto central da análise é o cálculo da política ótima, fundamentada em uma função objetivo da sociedade definida de maneira exógena. Em geral, não se considera a heterogeneidade dos indivíduos, bem como os efeitos sobre a escolha da política. Nessa forma de modelagem, os prováveis conflitos entre grupos não merecem atenção, tampouco são capazes de influenciar os resultados econômicos. Além disso, assume-se que o Estado é possuidor de todas as informações e meios necessários para a maximização da função de bem-estar social.

\section{O conceito de bem-Estar: afinal, do que estamos falando?}

É possível identificar dois conceitos de bem-estar predominantes na Teoria Econômica do Bemestar. O primeiro deles, associado à teoria tradicional, define bem-estar em termos de utilidade e é diretamente relacionado com a filosofia utilitarista. O segundo conceito está relacionado à eficiência e à otimização, com base na estrutura paretiana de análise econômica, e fundamenta a chamada Moderna Economia do Bem-Estar.

Ao se tratar o bem-estar em termos de utilidade, assume-se que o critério estabelecido para definir a condição de bem-estar de um indivíduo é a satisfação dos seus desejos ou prazer. São aspectos subjetivos, que podem se diferenciar entre os indivíduos. É necessário, portanto, caracterizar o indivíduo, normatizar o seu comportamento, a fim de possibilitar a análise científica e formal da condição de bemestar.

Conforme já exposto na seção anterior, o indivíduo se comporta de modo racional e esse comportamento racional representa o comportamento real. Agir racionalmente é agir buscando a maximização do auto interesse, não importa qual seja a motivação ou as consequências de tal maximização. Se todos agem motivados pelo auto interesse, então os indivíduos sempre preferirão mais a menos e não haverá espaço para o altruísmo ou para renunciar a algo em benefício do outro. Tal comportamento seria irracional.

Nessa estrutura de análise, não há espaço para o papel da ética na tomada de decisão. De acordo com Sen (1999, p. 31), “[...] considerar qualquer afastamento da maximização do auto interesse uma prova de irracionalidade tem de implicar uma rejeição do papel da ética na real tomada de decisão [...]”. 
Sen (1999) e Hirschman (1984) apresentam algumas críticas sobre ser o homo economicus (racional e maximizador do auto interesse) o indivíduo representativo do comportamento humano. Para Hirschman (1984, p. 95),

The efficient economic agent of traditional theory is essentially a silent scanner and "superior statistician" (Arrow, 1978) whereas I argued that she also has considerable gifts of verbal and nonverbal communication and persuasion that will enable ber to affect economic processes.

Ainda assim,

[...] apesar dessas (e de outras) críticas, a hipótese do comportamento puramente auto interessado permanece como a mais utilizada na economia, fornecendo os alicerces do comportamento para a teoria econômica e a análise da política econômica tradicionais e servindo de base para boa parte do que é ensinado aos estudantes de economia. (SEN, 1999, p. 33, nota 12).

Uma vez que a sociedade (o todo) é vista como a soma dos indivíduos (as partes), para analisar o nível de bem-estar social basta que os pressupostos adotados para o comportamento individual sejam expandidos para o comportamento social. Assim, o bem-estar social pode ser definido como o conjunto de maximizações do auto interesse individual. Haveria uma força equilibradora natural que garantiria que se os indivíduos de todas as sociedades agissem de modo racional, o bem-estar geral seria alcançado e mantido.

Observa-se que nessa estrutura de análise não há referência às dotações iniciais, sejam dos indivíduos ou das sociedades (conjunto dos indivíduos). Ao se admitir a existência de um indivíduo representativo, que maximiza sua utilidade e que age racionalmente, não se considera a heterogeneidade existente entre as pessoas, tampouco que os interesses dos indivíduos e dos grupos ou classes sociais a que estes indivíduos pertençam sejam conflitantes.

A condição de bem-estar ótimo paretiana, atualmente muito difundida na teoria econômica convencional, reforça a ideia de racionalidade como maximização do auto interesse. Sen (1999) afirma que a otimalidade de Pareto é um critério bastante limitado de avaliação de bem-estar. Para o aludido autor, in verbis, "Um estado pode estar no ótimo de Pareto havendo algumas pessoas na miséria extrema e outras nadando em luxo, desde que os miseráveis não possam melhorar suas condições sem reduzir o luxo dos ricos" (SEN, 1999, p. 48). Ou seja, a definição de um ponto ótimo não leva em consideração nenhum elemento distributivo.

Por extensão, um nível ótimo de bem-estar não necessariamente resulta em melhoria das condições de vida para grupos populacionais - ou indivíduos - que estejam em situação inferior à dos 
demais, seja do ponto de vista relativo ou absoluto. Na verdade, o nível ótimo está relacionado à eficiência econômica.

$\mathrm{Na}$ tentativa de dar à Economia um caráter mais científico e positivista, a complexidade da natureza humana foi abandonada pelos teóricos da teoria econômica ortodoxa e, por consequência, por muitos dos estudiosos da Moderna Economia do Bem-Estar. Com o intuito de se construir leis de funcionamento do sistema econômico baseadas no comportamento dos agentes, a análise econômica se tornou cada vez mais distante da realidade. Paradoxalmente, a sofisticação matemática - cada dia mais formalizada e complexa - foi acompanhada pela simplificação do modo de agir do indivíduo, resumido na maximização do auto interesse.

A respeito dessa simplificação da teoria econômica, Hirschman (1984) afirma que é preciso ser contrário a tal "parcimônia". Segundo este autor, "[...] the incredible complexity of human nature [...] was disregarded by traditional theory for very good reasons, but which must be spoon-fed back into the traditional findings for the sake of greater realism" (HIRSCHMAN, 1984, p. 95).

Para transformar o nível de bem-estar em uma variável tratável, passível de ser quantificada, recorre-se às proxies. A principal delas e hegemonicamente utilizada é a renda. No ambiente econômico, o indivíduo é considerado um consumidor que age racionalmente de modo a maximizar a sua utilidade (ou a atingir o ponto ótimo de eficiência máxima, no caso da análise paretiana). Os bens e serviços que ele consome representam o seu nível de utilidade, e quanto maior o seu consumo, maior o seu nível de utilidade e, consequentemente, maior o seu bem-estar. Dessa forma, o nível de bem-estar é definido com base na sua função consumo ou função utilidade (LADERCHI, 1997).

Uma vez que o determinante primaz do consumo é a renda, quanto mais elevada for a renda, maior é o nível de bem-estar. Está, portanto, estabelecida a relação entre bem-estar e renda e esta relação permeou - e ainda permeia - as análises de desenvolvimento e crescimento econômico. A renda é uma variável quantitativa, contínua, que permite a realização de análises matemáticas e estatísticas das mais diversas.

Dado que o bem-estar pode ser definido como a maximização do auto interesse e que a renda é a variável instrumental na análise de bem-estar, ações e/ou políticas que almejem o aumento do bem-estar objetivam ampliar o nível de renda. Porém, diante da racionalidade do indivíduo, a preocupação é com a ampliação individual da renda, sem envolver quais questões altruístas e distributivas. Em termos de bemestar social, o mesmo acontece. A teoria convencional do bem-estar parece desprezar o fato de que o indivíduo vive em sociedade e que suas decisões e ações não são tomadas de maneira independente do contexto social no qual ele vive e sem que sejam influenciadas por algum juízo de valor. De acordo com Hirschman (1984, p. 95), 
[...] another basic tension man must live with, this one resulting form the fact that he lives in society. It is the tension between self and others, between self-interest, on the hand, and public morality, service to community, or even self-sacrifice, on the other, or between "interest" and "benevolence" as Adam Smith put it. Here again economics has concentrated over-whelmingly on one term of the dichotomy, while putting forward simplistic and contradictory propositions on how to deal with the other.

A caracterização do comportamento individual e a conceituação do bem-estar feitos pela Economia do Bem-estar repercutem diretamente nas demais áreas do conhecimento econômico. Embora muitos não percebam, é sobre esses pressupostos que a maioria das políticas e ações econômicas são estruturadas. Não surpreende, portanto, o distanciamento não raro que tais políticas apresentam da realidade concreta das sociedades nas quais elas atuam ou para as quais foram formuladas. A ausência de elementos distributivos, históricos, sociais e éticos - este último muito bem argumentado por Sen (1999) contribuem para que as formulações propostas sejam muito mais abstratas do que reais. 


\section{Considerações finais}

A Economia, como área de conhecimento, é resultado de contribuições de pensadores e economistas das mais diversas ideologias e filosofias, o que por si só torna este ramo do conhecimento social aplicado encantador e desafiador. Ao longo do seu desenvolvimento, alguns conceitos foram se consolidando, a ponto de serem tratados como consensuais e pouco discutidos.

Parece ser este o caso do conceito de bem-estar. Embora abordada por muitos economistas da tradicional e da moderna Economia do Bem-Estar, a definição de bem-estar não recebe a atenção devida por aqueles que fazem uso dela. Na maioria das vezes, não se analisa as implicações dos pressupostos que sustentam tal definição, seja em termos de utilidade ou de otimalidade. As congruências e diferenças existentes entre a abordagem utilitarista tradicional, base do equilíbrio walrasiano, e a abordagem paretiana são escassamente apresentadas.

Em meio a uma perspectiva de análise fundamentada no individualismo metodológico, no afã de simplificar cada vez mais as relações econômicas, desconsidera-se a complexidade do agir do indivíduo. É necessário que as discussões e análises econômicas reconheçam a importância que definições, conceitos e pressupostos exercem nos seus resultados, abandonando a ideia de tomar tais elementos como dados e pré-definidos. 


\section{Referências}

ARAÚJO, L. S. de O.; MENDONÇA, H. F. de. Mercado e Estado: Uma síntese da evolução da economia política moderna. In: CONGRESSO BRASILEIRO DE HISTÓRIA ECONÔMICA, 5., 2003, Belo Horizonte. Anais... Belo Horizonte: ABPHE, 2003. Disponível em:

<http://econpapers.repec.org/paper/abphe2003/>. Acesso em: 01 nov. 2016.

BLACKORBY, C.; BOSSERT, W.; DONALDSON, D. Utilitarianism and Theory of Justice. Discussion Papers, Nottingham, n. 30, 1999. Disponível em:

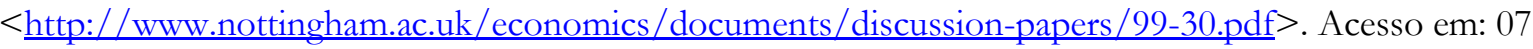
nov. 2016.

GANEM, A. Demonstrar a ordem racional do mercado: reflexões em torno de um projeto impossível.

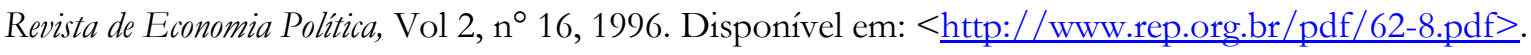
Acesso em: 01 nov. 2016.

GARCIA, F. (Apresentação) In: PARETO, Vilfredo. Manual de Economia Política. São Paulo: Nova Cultural, 1996 (Coleção Os Economistas).

HIRSCHMAN, A. O. Against Parsimony: three easy ways of complicating some categories of economic discourse. American Economic Review, v. 74, 1984, p. 89-96. Disponível em:

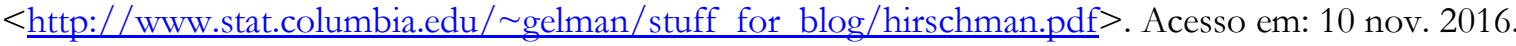

LADERCHI, Caterina Rugger. Poverty and Its Many Dimensions: the role of income as an indicator. Oxford Development Studies, Oxford, v. 25, n. 3, p. 345-360. 1997.

LIPSEY, R. G.; LANCASTER; K. The General Theory of Second Best. The Review of Economic Studies, vol. 24, n. 1, 1956. Disponível em: < https://www.jstor.org/stable/i339922>. Acesso em: 10 nov. 2016.

PARETO, V. Manual de Economia Política. São Paulo: Nova Cultural, 1996 (Coleção Os Economistas). 
REIS, Márcio Carneiro. Estado e mercado na teoria econômica e na história do capitalismo: uma introdução ao estudo da

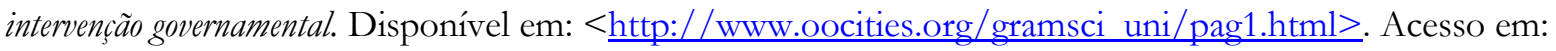
08 nov. 2016.

SEN, A. Sobre Ética e Economia. São Paulo: Companhia das Letras, 1999.

SOUSA, Luiz Gonzaga de. Economia do bem-estar. Observatorio de la Economia Latinoamericano, n. 158, 2011. Disponível em: < http://www.eumed.net/cursecon/ecolat/br/11/lgs.html>. Acesso em: 02 nov. 2016.

Recebido em: julho de 2019. Aprovado em: dezembro de 2019. 